\title{
A Study on Methods of Literature Education in Vocational Colleges based on Students' Experience
}

\author{
Feng Jie \\ Chongqing Vocational Institute of Safety \& Technical, Chongqing, 404020, China \\ fengjiecq@126.com
}

Keywords: Student experience. Vocational college. Literature education research. Educational method. Effectiveness.

\begin{abstract}
As the expression form of human aesthetic emotion and life feeling, literature plays a very important role in the perfection of human nature and the development of society. However, in vocational colleges, literature education is a phenomenon of instrumentalist, emphasis on skills and neglect of humanities, which seriously restricts the improvement of students' literary literacy and comprehensive quality. Students' life experience, literature experience, cultural experience and artistic experience can form four dimensions of literature education. It is an effective platform for literature education. Teachers should be full of enthusiasm for literary education, pay full attention to, promote students' four-fold experience, and innovate literature.
\end{abstract}

\section{Introduction}

Gorky once put forward that "literature is human studies", that is, literature has the comprehensive characteristics of language art, emotion, aesthetics, philosophy and so on. Literature education can not only teach students the knowledge of Chinese instrumentality. What is more important is that literature, with its rich emotional connotation and profound philosophy of life, creates a kind of aesthetic atmosphere for students, introduces them into the aesthetic realm of life, and finally achieves the goal of literature education-to improve the moral level of students. Cultivate students' aesthetic ability.

\section{Problems in literature education in Vocational Colleges}

The marginalization of literature education, the school does not pay attention to, the student study enthusiasm is not high. With the deepening of reform and opening up, the market competition is becoming more and more intense, and the employment situation of students is becoming more and more severe. Vocational colleges and universities often adjust their talent training programs and set up study courses according to the job requirements and market demands. Accordingly, the school will focus on the cultivation of students' professional skills, increase the proportion of professional courses, but ignore the students' literature education curriculum, resulting in the loss of students' humanistic literacy. Schools have formed a consensus that professional learning should be the focus to meet future professional development needs. Under such guidance, students also It is believed that the focus of study should be on professional skills, when they are confronted with contradictions between basic and professional courses, they will definitely abandon basic courses, so their enthusiasm for Chinese learning is not high.

\section{The characteristics of Chinese Teaching in Contemporary Vocational and Technical Colleges}

The vocational education in contemporary China is adapted to the requirements of the modernization construction of our country. It has comprehensive professional ability and is directly 
in the production, service, technology and management of the first line of work, higher application-oriented professionals and workers. With its particularity, this kind of market orientation makes people first think of how to train students into a person who is directly useful to society in order to adapt to the choice of real society. Therefore, we need to completely change the concept of education and apply the idea of humanistic education to the whole process of vocational education. Chinese is an important basic discipline, tool discipline. The level of students' Chinese quality not only affects other subjects their study will have an important impact on their future work and life. Chinese teaching should be the overall development of human beings, all human thinking and technological innovation reserved space, so that students and their thinking and technological innovation in the space to obtain greater development. Vocational students should not only learn the basic knowledge of Chinese, master the basic skills of Chinese, but also acquire a profound humanistic accomplishment.

\section{The advantages of traditional Chinese teaching methods should maintained in Teaching}

Adhere to the principle of unity of culture and Taoism. In ancient China, the ideological content of Chinese articles called Tao, and the linguistic expressions of articles called "Тao".

Text in Chinese teaching, the basic knowledge of Chinese language teaching and reading, listening, speaking, writing basic skills training, using Tao to refer to ideological education. An article is a unity of thought and language expression. The unity of culture and Taoism requires Chinese teaching to take into account the two factors of Chinese training and ideological education according to the dialectical unity relationship between ideological content and expression form. Make both complement each other, promote each other, in order to improve the efficiency of Chinese teaching. Strengthen the combination of reading and writing training. From the perspective of reading training In order to acquire the basic knowledge of language, words, rhetoric, logic, literature and so on, and to cultivate the abilities of observing, thinking, imagining, and so on, they can be improved both in the aspects of literature and Tao. It can also enable students to transform the humanistic accomplishment gained from reading model articles into expressive ability, that is, the ability to express the ideas of speaking and writing, the selection of materials, the arrangement of texts, the construction of sentence words, and so on. We should be able to practice more precisely and be able to combine points and faces. In Chinese teaching, more practice is to let students fully move their mouth, hands, brains, reading, expression and other activities, so that they can learn, listen, speak, write and other basic skills while mastering the basic knowledge of Chinese. This is the language discipline foundation tool nature decides. To master the tool of Chinese, we cannot rely solely on teachers to explain it, nor can we rely solely on the memorization of knowledge terms, and must rely on more practice. This is also necessary for the development of students' intelligence in the middle and professional stages. In order to cultivate the students' observation, thinking and imagination, we must rely on more practice. There are many ways to practice. Comprehensive written composition, oral composition is practice, other such as reading, silent reading, dictation, answering and so on are also exercises. More practice includes not only certain quantity requirements, but also certain quality requirements. According to different teaching objectives and different teaching objects, the most effective methods should used. From the above several aspects, we can see that Chinese and Chinese teaching is not only a means of communication, but also a kind of cultural composition and the guide of mastering its deep connotation. Therefore, Chinese teaching in vocational colleges must be re-examined and orientated according to the inherent characteristics of vocational schools. Based on maintaining and giving full play to the traditional Chinese teaching methods and methods, the course reform carried out boldly, and some new and dynamic ideas applied to the teaching. 


\section{The value of Student experience: Necessary Curriculum of Resources}

\subsection{Preparing lessons: not only knowledge, but also students' experience.}

Preparation for lessons is the preparation and planning of teaching before class, and is the starting link of the completely teaching work. In traditional education, the focus of teacher preparation is often on the knowledge point, more on how to decompose the teaching knowledge in order to complete the teaching task, never taking into account the students' experience. Students' experience, such as knowledge, skills, emotion, attitude and values, can take into account when teachers prepare lessons.

Teachers do not teach for the sake of teaching to guide their teaching by taking into account the students' learning. Teachers are more concerned with how to make students want to learn than with what they want to learn. How to find out the previous experience of students is what teachers need to know in preparing lessons. Only in this way can the students' interest in learning be aroused through situational teaching method at the beginning of class to arouse the students' mood of active learning.

A student is an active subject; he does not enter the classroom with his head empty. Before entering class, students have their own unique experience. The task of a teacher is to take into account the students' existing experience when preparing lessons and then what teaching methods can be better linked to the students' previous experience. This is the only way to better mobilize the enthusiasm of students to learn. Let students want to learn actively, not because of external pressure to learn.

\subsection{Class stage: pay attention not only to knowledge, but also to students}

The teaching of knowledge is one aspect, but more important is to pay attention to every student. Because of without the participation of students' experience, the study of subject knowledge will be even inefficient or ineffective. Moreover, the classroom is not only a place for learning subject knowledge, but also a place for nurturing human nature. In the process of teaching, we must pay attention to students' emotional life and emotional experience, to their moral life and personality formation. In a word, the teaching should return from the single knowledge to the true teaching: pursuing the students' active, true and healthy development.

Classroom teaching changes from paying attention to subject knowledge to paying attention to the process of children's learning knowledge. The real experience and feeling of children require the elimination of the teacher-student relationship, which is dominant by teachers, to construct a kind of harmonious relationship between teachers and students. Interactive educational relationship, in which teachers and students share common knowledge, meaning and value, meet in sharing, understand and construct shared value. Students' life experience is the starting point of their education, and the difference of students' personal knowledge, personality and thinking mode is a kind of curriculum resource to be developed. Students' understanding of learning content, no matter how young, no matter how novel Both reflect the experience of students and their own views, which is a valuable curriculum resource. Teachers should allow it to enter into the teaching process, so that the teaching process becomes a real dialogue and communication, intertwined with the process of understanding and moving.

\subsection{After-class stage: The end of Teaching; The growth of students' experience.}

The starting point of teaching is student experience, and the end of teaching must be the growth of student experience.

In comparing traditional education with progressive education, Dewey pointed out that the teaching materials used in education consist of a series of knowledge and skills that had compiled in the past. Therefore, the school's main task is to transfer these knowledge and skills to the new generation. In this way, what we acquire is dead book knowledge. We learn new knowledge by 
memory and retelling, and we do not construct our own unified knowledge system. Knowledge of real educational value should be a kind of wisdom that can internalize by students and can used to guide specific affairs at any time.

The difference between adult creation and children's experience and ability is such that students cannot participate actively in the development of teaching content. Their standard is to do as usual-to learn, just as 600 soldiers have a duty to fight finally. In this case, learning simply means acquiring what is already in the books and in the minds of adults. Moreover, what taught thought to be essentially immutable. What taught regarded as a finished product, and therefore does not concern itself with how it built up or with the changes that will inevitably take place in the future? We focus more on what students learn than on what they learn. Therefore, the end of teaching can only rest on the growth of students' experience. Students must reflect and digest the contents of the classroom, internalize their own wisdom, which can use at any time to guide the follow-up experience.

It is important for students to master systematic knowledge, but at the same time, it must noted that abstract knowledge, which is divorced from students' direct experience, is only an abstract symbol for students, and it cannot enrich students' minds and minds. A meaningful teaching process, in addition to the characteristics of learning knowledge, should also be a process of continuous growth of students' experience. Therefore, students' experience should always revolve around in the preparation stage, in class and even after class.

\section{Teaching method}

Excellent teaching experience, carried out throughout the teaching process, overall, the cultural foundation of the students admitted to vocational schools is relatively weak. Even some secondary vocational students enter the school without passing the examination, and most of the students come only to learn a skill. Some students do not even have the basic ability of listening, speaking, reading and writing, not to mention the analysis and appreciation of literary works, and only some anecdotal things in the classroom can arouse their interest. Thus it can be seen that there is no conflict and contradiction between the cultivation of Chinese basic ability and the implementation of humanistic education, so long as the proper method is used to guide correctly, we can get twice the result with half the effort. Part one of Chinese Teaching An important task is to create a good educational environment for students, to free students from the passive state, so that he can improve based on the original.

\section{References}

[1] John. Dewey, experience and Nature [M]. T sung-first, Shanghai: business Press, 1960: 10.

[2] Chen Yi. Experience and Democracy-the fundamental study of Dewey's political philosophy. [M]. Fu d University Press 2002 (12).

[3] Li Jiao. On the Development Strategy of students' experience as Curriculum Resources [J]. Modern Educational Science 2007 (2).

[4] He X m. Teacher can not ignore the curriculum resources: student experience [J]. Modern Educational Science 2008 (3).

[5] Dewey. Dewey's selected works on Education [M]. Chao Xiang-l, Wang C x. East China normal University Press 1981: 347

[6] Jiang D Yuan’s Twelve views [E B / O L] .http: / www. cvae. com. cnr. 2012-06-30.

[7] Chen Xiaoping. A study on the Teaching Reform of Chinese language and Literature in Vocational and Technical Colleges [J]. New Educational Age Electronic Journal (teacher Edition) 
2015 (4): 144.

[8] Li Han. On the Teaching of Chinese language and Literature in Vocational Colleges [J]. Career 2014 (21): 141-141.

[9] Wang foam. Socialized Reform of Chinese language and Literature Education in higher Vocational Education [J]. Modern vocational education 2016 (3): 63.

[10] Chen $\mathrm{H}$ y. Problems and Countermeasures in the Teaching of Chinese language and Literature in higher Vocational Education [J]. Book Digest 2017 (7): 26-27. 